\title{
Uploading Social Media as Indirect Promotion Strategies in Film Destination Tourism: Re-Enactment of Ada Apa dengan Cinta 2 in Sellie Coffee
}

\author{
Ju Hee Bhin \\ Universitas Gadjah Mada, Indonesia \\ Email: ju.hee.b@mail.ugm.ac.id
}

\begin{abstract}
This study aims at understanding tourist activities and re-enactment of AADC 2 that can potentially be an indirect promotion strategy of Sellie Coffee. Uploading photography of the reenactment of AADC 2 in social media leads to a sensational indirect promotion strategy that needs to be paid any attention. This study is conducted in Sellie Coffee, located in Jalan Prawirotaman, Yogyakarta, Indonesia. This research employs qualitative approach and all the data is obtained through literature study, observation, and interview. The research results show that Instagram, one of a popular social media, provides a complete communication facility, from tourism branding to usergenerated content photography. Moreover, the activity of uploading photos related to AADC 2 in Sellie Coffee visited by film tourists in social media has become one of indirect promotion strategies.
\end{abstract}

Keywords: film tourism, re-enactment, AADC2, Sellie Coffee, indirect promotion strategies

\section{Background}

Today, film and tourism have strongly bonded each other and cannot be detached as it gives a fast-growing phenomenon worldwide, fueled by both the growth of the entertainment industry and the increase in international travel. As media has become easily accessible and pervasive, entertainment is enjoyed and consumed by mass audiences as a means of joy, pleasure, day dreaming and fantasy, as well as understanding of others in everyday life (Carey, 1988; Urry, 1990).

As social media has become a part of people's everyday lives, people have started to post pictures of re-enacting film on their social media. It is a matter of time that people can see another people's re-enactment online. As Bourque (2009) underlines "Social media is reshaping the world we live in. Greater connectivity with friends and family gives 'word of mouth' new meaning, advice on what products to buy and what brands to avoid is only a mouse click away. Social media is reaching deep into our everyday lives, including affecting things like how we travel". It is clearly identified that through media, people can gather and use information from various sources to develop a perception of the destination (Robinson, 2013).

Eventually, the social media process of tourism has become more dependent on how people capture and tell a story about film destinations. Unintentionally, this phenomenon leads to indirect promotion strategies of film destinations. Promoting tourism online has become one of the efficient marketing in the tourism industry, as it is easy to find information regarding locations in modern times due to users becoming more mobile and their roles getting active in the ongoing relation with the media.

One of a film that developed several film tourism locations successfully is the film $\boldsymbol{A A D C} \mathbf{2}$ directed by Riri Riza in 2016. The film managed to 
attract the audience attention with the background and the atmosphere of Yogyakarta such as historical sites, culinary and artistic places to make the audience enthusiastic to visit the location of the filming. According to the data of the last audience, $A A D C 2$ became the film with the second highest number of viewers in 2016, reaching 3,665,509. Among the locations that became famous, Sellie Coffee was one of the places that widely known to the audience. Despite the unintentional participation of Sellie Coffee in the film, the film became one of the new and different options as a promising promotional media.

\section{Theoretical Framework}

When audiences watch films, the film's personalized storylines touch on shared human interests and experiences which anyone can identify with in his or her everyday life. It may allow audiences to feel like they are participating in a real story which is happening right next to them, empathizing with the characters and caring about what happens to them (Carroll, 1996; Creeber, 2001: 439-455; Kincaid, 2002:136-152; Hobson, 2003). Kim (2010) suggest short re-creations and film re-enactments are one of the physical location encounters. Kim also mentioned, in shot re-creations, film tourists are trying to find the exact film angles and then take pictures as posing as one of the characters. In these cases, disappointments may occur if the original filming spot is not accessible. Film re-enactments are a form of role-play where the characters are quoted and also dressing up being part of this phenomenon. Although this theoretical basis will be used as one of the references the researcher will identify whether tourists who visit Sellie Coffee are re-enacting AADC 2 after watching the film.

Photographs create an essential part of selective memory of a particular time, place and performance that enriches the tourist experience (Markwick, 2001; Haldrup and Larsen, 2003; Burns, 2004; Morgan and Pritchard, 2005:417438.). In some cases, photographs provide the purpose for tourist experiences (Burns, 2004:255275). These visual narratives, framed in the form of tourist photographs, constitute a personal image and experience that tells a unique story of an exceptional and extraordinary encounter, which provides crucial components of "place-myths" (Shields, 1991). Hence, this "emblematic tourist practice" (Haldrup and Larsen, 2003: 23-45) becomes transformed from merely visual artifacts to symbolic objects that are constituted in, and convey subjectivities of, their circulation (Crang, 1997: 359-373).

According to the UNWTO (1999), internet is a noticeable tourism actor and has a significant role for the travel and tourism industry. Considering the huge number of web users, the internet can reach more people and therefore attract more tourists than any other traditional media such as television or travel guides (UNWTO, 1999: 54). Moreover, it is a crucial distribution channel via which tourism organizations can promote their destinations and products offered by service providers. Promotion is the element in a marketing mix that serves to inform, persuade, and remind the market of the organization and its products.

According to Fyall, Fletcher and Spyriadis (2009:115), tourist destinations and products are better promoted via internet. Social media is one of the most effective internet-based applications which allows interactive and direct relationship between customers and the tourism industry. Tourism can be promoted when there is effective communication with the potential and actual tourists. The basic application of social media is a consideration phase tool that connects post-purchase experiences with potential customers progressing from awareness to purchase (Evans, 2008). In social media industry, electronic word of mouth (or eWOM) phenomenon is happening, where positive or negative statement made by potential, actual, and former customers about a product or a company via Internet (HennigThurau et al, 2004). eWOM communication can take place in various settings and consumers can post their opinions, comments and reviews of products on social network. Eventually people can exchange multi-way of information among the small groups of individuals in asynchronous mode (Hung and Li, 2007). Indirect promotion is often employed by businesses on social media since the advantage of indirect promotion is that it allows an organization to be more authentic and natural with the ways it communicates to potential customers in high speed.

A research of re-enacting and photographing at screen tourism locations by Sean Kim (2010) 
suggests how screen tourism locations and their association with tourists' experiences are (re) produced, contextualized and performed through production and consumption of a Korean television drama series entitled, Winter Sonata. The research was based on visual image analysis and examines the context and meanings of photographs taken by tourists who are re-enacting scenes from the series during their visit to Nami Island, the main filming location of Winter Sonata, in South Korea. The research concluded that viewing experiences also induced the audiences to visit the filming locations and to perform reflexive and extraordinary touristic experiences in the form of re-enacting scenes from the series and photographing their re-enactment.

Those companies that devote resources toward developing indirect advertising techniques are often able to establish long-term relationships with customers because there is not as much pressure for potential customers to make a purchase.

\section{Research Method}

This study is a qualitative research which covers a broad range of approaches that are linked to different theories about what there is to know about social communities and how to find out about it. Although definitions vary, the aims of qualitative research are generally directed at providing an in-depth and interpreted understanding of the social world, by learning about people's social and material circumstances, their experiences, perspectives and histories (Denzin \& Lincoln, 2005). The researcher will generate a natural occurring such as observation and analysis of documents, conversation and discourse provide an 'enactment' of social phenomena in their original settings. Denzin \& Lincoln (2005) suggests generated data such as those provided by in-depth interviews and focus groups yield a 'recounting' of phenomena originated specifically for the research study.

\section{Research Findings and Discussion}

According to analysis of the tourist activity in Sellie Coffee shows the potential to be indirect promotion strategies. Uploading photography of the re-enactment of AADC 2 on social media leads to sensational indirect promotion strategies that we need to pay attention to. 872 customers visit the Sellie Coffee and out of those customers, 20 film tourists holding a camera and visiting from other regions such as Jakarta, Surabaya, Palembang, Bandung, Medan, and Bekasi were interviewed.

\subsection{Tourist Activity in Sellie Coffee}

Film tourists of AADC 2 who visited Sellie Coffee had showed similar performances which the researcher assumed as tourist activity. Interestingly, they all hold cameras or use camera phones to take good quality photographs of the surroundings of what they have seen exactly in the film. Since photographs activate both 'imaginative mobility' and 'memory travel', they frame tourists' gazes and the manipulation of their cameras. If photographs of surrounding is the basic performance shown by tourists, photographs of re-enactment will be a significant moment for them. As the reunion scene of Cinta and Rangga was filmed in Sellie Coffee, film tourists are interested in experiencing locations from the perspective of the beloved characters. Photographs are more than just representations, and while photographic images are caught up with the moment, photographic objects have temporal and spatial duration. Additionally, the re-enactment and the meaning of what they did tends to be similar to Cinta and Rangga reunion scene in AADC 2.

As mentioned above, photographs create an essential part of the selective memory of a particular time, place and performances, and it has become a compulsory activity for tourists during their travelling. A film tourist Siti, asking her friend to take a picture in front of the café where the sign "Sellie Coffee" is displayed. Siti wanted to show her friends that she has visited the café, and according to her, the sign was the only way to prove to her friends that she had visited Sellie Coffee. Generally, film tourists tend to take pictures with the sign that represents the location such as the name of the place.

In the case of film tourists who are embarrassed to ask other to take pictures or has no one to take pictures for them tend to take selfies to not interrupt other customers. Those who take selfies do not re-enact the reunion scene, but take it to keep it as evidence of their visit to Sellie Coffee, likewise taking pictures in front of the sign. Most phone models have front cameras where people 
can easily take pictures by seeing their faces in the screen for convenience.

\subsection{Re-enactment of $A A D C$ reunion scene in Sellie Coffee}

Films create destination awareness, consciousness, and images, which result in the development of a stronger interest in a destination. The films also develop imagery, myths, icons, and emotions or sentiments. Tourists with a higher degree of involvement not only perceived a higher degree of satisfaction with their film tourism activities but also were more willing to reenact dialogues or scenes from the film in order to experience the filmed landscapes from the film characters' perspectives. The storylines of AADC 2 allow audiences to feel that they are participating in a real story which is happening just next to them, empathizing with the characters and caring about what happens to them (Carroll, 1996; Creeber, 2001; Kincaid, 2002; Hobson, 2003).

\section{"Rangga... Apa yang kamu lakukan ke saya itu jahat"}

(Rangga... after all what you have done to me is mean)

The short script above was from the scenes of AADC 2 in which Rangga and Cinta, two main characters in the film sit facing together in Sellie Coffee. One of the example ... Uwie, a film tourist has uploaded her photography in Sellie Coffee along with dialogue that the researcher has mentioned above. The reuniting scene has contextualized symbolic meanings that create Sellie Coffee as one of the popular locations than other AADC 2 shooting place. In this way, the table and chair are actively used as a performance stage upon with tourist's own narratives and discourses are played out and re-interpreted through the re-enactment and photography against the backdrop in terms of the events in the series. When film tourists visit film locations, their personal attachment with the locations can partially be understood as symbolic memory.

Adel, a film tourist, wanted to show her own style of re-enactment, and by seeing this photograph people can still understand the meaning of the photograph. Some film tourists show different styles of re-enactment to translate into more playful, sensuous and even serious ways of being there, which connotes authentic film tourist experiences in the film tourism location. During the researcher's observation, a film tourist Siti, asking her friend to take a picture in front of the café where the sign "Sellie Coffee" is displayed. Siti wanted to show her friends that she has visited the café, and according to her, the sign was the only way to prove to her friends that she had visited Sellie Coffee. Generally, film tourists tend to take pictures with the sign that represents the location such as the name of the place. The bench and camera angle are actively used as a performance stage upon which tourists' own narratives and discourses are played out and re-interpreted through the re-enactment and photography, against the backdrop in terms of the events in the series.

\subsection{Uploading on Social Media as Tourist Activity}

Previous tourist activity in film locations were film tourists taking photos of their film re-enactment, which they have kept to themselves or lay aside. However, current tourist activity has added up into uploading their re-enactment moments on social media to share with their social community. During the observation period, eight hundred seventy-two (872) customers visited Sellie Coffee and out of those customers, five hundred ninety-seven (597) have watched the film AADC 2, and around 70\% are people who uploaded the re-enactment picture on social media. The accessibility of social media is uniquely easy, so that potential consumers enable to acquire and share information online by uploading pictures, and sharing the experiences with their social media users. In addition, they share information and knowledge about the product and services as well. Li and Wang (2011) and Thevenot (2007) defined social media as the internet evolving from a broadcasting medium to a participatory platform that allows people to become the "media" themselves for collaborating and sharing information.

Since the release of AADC 2, the number of visitors in Sellie Coffee has risen 50\%. Even after the film has not been screening in cinema, the number of visitors maintained a percentage of approximately $20 \%$ until now. Indeed, Wisnu, the 
owner of Sellie Coffee and the staff can still find several customers photographing the re-enactment of the film AADC 2 in Sellie Coffee. In effect, they also experience visitors who visit Sellie Coffee after collecting information relevant on the café from their friends' posts on social media.

As this spontaneously became an indirect promotional activity for Sellie Coffee, Wisnu provided a Wi-Fi router in the café in March 2017, contributing to the indirect promotion done by the visitors. Furthermore, Wisnu and the staff asks visitors to upload photos and videos that visitors have taken in Sellie Coffee on social media to update the photographs.

In terms of tourism, this tourist activity provides tourists with opportunities to publish their recommendations, reviews and photographs on social media to other tourists who can thus plan their journeys without necessarily consulting the tourism industry's brochures and home pages. Lately, this feature of user-contributed travel reviews is perceived as being more sincere than the always glossy brochures and home pages of the tourism industry.

\subsection{Social Media as Indirect Promotion Strategies}

In terms of tourism, tourists can actively make their own sense and explanation of locations, tourist activities and tourist objects. Therefore, through social media the users can collect memories of real experiences before they head to the destination. A tourism including ingredient, turning destinations of little or no importance to tourists, into much visited tourist attractions, for instance Sellie Coffee which was one of the locations for the film AADC 2. Additionally, Wisnu and the staff asked the visitors to click likes and leave comments in the posts of the official Instagram account of Sellie Coffee. This could be a new way of communicating directly with customers and among the customers as well, the cheap and specialised promotion of places and services, insight into the rating of one's own and competitors' services and so on.

Instagram is an online photo and videosharing medium owned by Facebook that was launched in 2010, and it has grown steadily and strongly until today. According to Internet Live Statistics (2016) there are 487 Instagram photos uploaded each single second, and around 43 million photos being uploaded every single day. As a mobile application, Instagram can be accessed from smartphones such as iPhone and phones using the Android platform. The application allows users to upload photos and videos to the service, which can be edited with various filters, and organized with hashtags and location information. An account's posts can be shared publicly or with pre-approved followers. Three years after being launched, the estimated number of users of Instagram was 100 million users, and approximately four billion photos were uploaded and displayed (Abbott et al., 2013).

The world of marketing is changing rapidly with technology is dominating our lives. In order to keep up with the pace, marketers must have a strong mind, wide knowledge and most importantly, flexibility to the marketing movements. In the tourism sector, Instagram has a role as an online photo-album that can be accessed by others and users can also use it as a promotion channel. However, it is important to point out that the process of promotion on Instagram is different with conventional media such as print and electronic advertising. The strength of Instagram as "self-promotion aid" is its ability to change users to become a potential marketer for each visual material uploaded.

Today, tourists upload their travel photographs and videos upload to Instagram to share their travelling moments to millions of users. Hence, the form of shared experience or interactions among users on Instagram is different. Various interactions such as like, comment, or even including hashtags will be signs of a particular object. Also for some people, they justify their travelling by showing photos or videos and somehow they feel selfsatisfaction in seeing their posts on Instagram.

Without exception, film tourists of AADC 2 upload their photographs of Sellie Coffee on Instagram. During the observation, the researcher observed Jannis, a film tourist, uploading her photograph of re-enactment on Instagram right after she took a picture during her visit to Sellie Coffee. Likewise, Jannis can edit the photograph using different filters and make it a good quality photograph before she uploads it onto her social media. Above all, the process of uploading and the internet speed nowadays allows Janis to upload in an instant. Thus, any Instagram user can be easily 
redistributed to significant others at-a-distance or exhibited in virtual space.

\subsection{Hashtag (\#)}

Evans D. (2008) said that a hashtag (\#) is a type of metadata tag used on social networks such as Twitter, Instagram and so on, allowing users to apply dynamic, user-generated tagging which makes it possible for others to easily find messages with a specific theme or content. Users create and use hashtags by placing the number sign or pound sign (\#) in front of a string of alphanumeric characters, usually a word or unspaced phrase, in or at the end of a message. The hashtag may contain letters, digits, and underscores. Searching for that hashtag will yield each message that has been tagged with it. A hashtag archive is consequently collected into a single stream under the same hashtag. For example, on the photo-sharing service Instagram, the hashtag \#aadc2 allows user to find all the posts that have been tagged using the same hashtag. Jannis, a film tourist, built a network with other Instagram accounts with "aadc2" and "selliecoffee" label. It indicates that the network with "aadc2" and "selliecoffee" label is to capture and share tourism destination to the other users.

Moreover, with so many people posting on social media, it could be hard to find the posts that the users want to read, and also difficult to find people who discuss topics that interest them. There is so much information being posted at any one time that wading through them is time-consuming, and many interesting things can be overlooked. Hashtags help solve that problem by making it easy to search for posts with hashtags that are particularly interesting to users.

In social media, people click the "like" button with a shape of heart below the post to let people know that they enjoy it without leaving a comment, and "like" is visible below the post. For example, a person clicks "like" below a friend's video and people including the friend will be able to see the number of "like". The potential to get responses from their friends is a major motivator of social media activity, and most of them provide plenty of feedback to online friends. Several marketers focus on getting more "like" because the more they get the easier their posts will be shown on social media and eventually people can see. In terms of Sellie
Coffee, tourists posting their pictures during their visit to the café and getting more "like" can make it easier to be searched on social media.

The users simply click the heart shape which represents "like" sign Instagram, and later everyone can see the number of likes the posts have received. As mentioned above, top posts categories are for posts with many "like" and Jimmy who received 289 likes in the post where he took a photograph in front of Sellie Coffee was placed in the top post on Instagram. Therefore, when other users search for Sellie coffee using \#selliecoffee they will view Jimmy's post first.

Not only clicking on "like" but writing comments below the posts are available in social media and is shared publicly where communications can happen in the posts. Irwan, a screen tourist, reenacting the reunion scene of AADC 2 in Sellie Coffee, and mentioned the dialogue as well in his Instagram. On the right side of the comment list, a person asks about the location of where he took the picture and this could be answered by anyone who knows the place. Therefore, the person can get the information without searching on Google.

While word-of-mouth recommendations have always been a crucial factor in triggering journeys to particular places, they were traditionally confined to a small world of friends, family members, and co-workers. 'Electronic word-of-mouth' or eWOM does not know such a restricted world, since it is in a global scope. Given that tourists rely more on such search engines to locate and compare travel information, it is unsurprising that research shows that favourable recommendations, or eWOM, are good for business (Litvin et al., 2008).

The strength of Instagram as "self-promotion aid" is its ability to change users to become a potential marketer for each visual material uploaded. Based on the observation, the researcher analyze that Instagram becomes the favorite channel for promoting destination images by tourism operators. For example, the admin of @selliecoffee admits that the emergent of their Instagram account is based on market demand of easy, faster, and cheap tourism providers. Hence, this is clear to point out that the promotion by Instagram is different with conventional promotions. However, conventional promotions need high cost but being mainly a photo-sharing application, Instagram has excelled 
as an effective communication and marketing tool to display products with visual descriptions. Hence, it instantly becomes a useful social networking platform instantly to individuals and companies.

Moreover, indirect promotion means that consumers are better informed than ever beforenot only being able to add their own comments, but also being able to find other information and articles and 'tag' them with their own keywords for search purposes. These facilities enable to act as a low-cost promotion channel to develop tourism destination. It is clear that many motivations for posting content depends on the person and the context.

According to Beerli and Martin's model of formation of destination image, there are two determining factors that influence the form of destination image (Beerli and Martin, 2004: 660). First factor is the personal factors including motivation, vacation experience, and the characteristic of socio-demography. The second factor is information source, including the type of individual in disseminating information and intensity of visits to tourist destinations. Through both, the tourist activity can be explained that both of them have potential value to continue, freeze, and create a new image for Sellie Coffee. For example, many photos that were uploaded by different users through the hashtag \#selliecoffee, or tagging@selliecoffee, some of them show the same characteristic as an old photograph. The old photograph means that the photo was reproduced with new filter and narration. Therefore, users can still identify that the object in the photograph is Sellie Coffee, though the photographer tried to take photos from different angles. The different findings the researcher have encountered in the second account, where photos are produced tend to create a new image of Sellie Coffee. The researcher sees that, tourist activity is the most valuable aspect to encourage users to promote Sellie Coffee.

The study in this tourist activity shows that the image formation of tourism destination through not only by visualization of photography, but the process also involves a shared experience of users. In other words, for the formation of destination branding through Instagram, there are a few steps that must be taken. Starting from posting photos, sharing an experience, and of course getting feedback from users' comments and discussion.

\section{Conclusion}

Sellie Coffee shows the transformation of a nontourism place into shared places (McKercher, 2015), where tourists and locals coexist and share the functions of the destination on Instagram. These changes are collectively referred to as AADC 2 impacts and inevitably result in continuous changes to tourists' experiences. Moreover, to some film tourists in Sellie Coffee may have similar expectations and want to have similar but self-reflexive experiences, by doing similar tourist activities. Due to that, other screen tourists at Sellie Coffee seemed to be supportive of each other to enable other film tourist in getting a better reenactment and photograph.

Reenactment of AADC 2 in Sellie Coffee not only creates personalized memories and attachment with its filming locations, but also create new touristic spaces and inspire the visitors to enhance their touristic experience in the form of re-enacting a scene from the film and photographing their reenactment. Furthermore, the film AADC 2 became the first subject to introduce Sellie Coffee to the public, and afterwards social media expanded the effect of indirect promotion through the continuous message updates. Social media such as Facebook, Twitter, and Instagram, and so on give a big influence to the public. As a result, the activities of uploading photos in film locations visited by film tourists on social media nowadays has become one of the indirect promotion strategies.

This research study discussed possible directions and areas for future film tourism research in Indonesia. Following a broad search of the existing research on film induced tourism in Indonesia, it was observed that the literature review on film induced tourism is somewhat scarce, which is in all probability due to its relatively short history. The findings of the tourist survey and the strategic conversations highlight a number of implications for the future development of such destinations. These implications include successful use of destination branding in the promotion of a film location. It has been shown that film induced tourism has the potential to offer many opportunities. For further research, finding the disadvantages of tourist activity in Sellie Coffee as long-term planning to have more data, which means using as quantitative analysis may find strong arguments on the influence 
of tourist activity as indirect promotion strategies in Sellie Coffee. Hence this research hopefully can be used as a reference for further research.

\section{References}

Abbott, W., Donaghey, J., Hare, J., \& Hopkins, P. (2013). An Instagram of worth a thousand words: An industry panel and audience. Library Hi Tech News, 30 (7). 1-6.

Adler, J. (1989). Travel as performed art. American Journal of Sociology, 94, 1366-1391.

Altheide, D.L. (1997). Media participation in everyday life. Leisure Studies, 19, 17-29.

Amaro, S. and Duarte, P. (2013). Online travel purchasing: a literature review. Journal of Travel \& Tourism Marketing, 30, 8, 755-785.

Rahajeng, A. (2008). Factor analysis of cultural, historical and natural tourism determinants in Yogyakarta: Domestic tourists' perspectives. Economic Journal of Emerging Markets, 13.

Beerli, A., \& Martín, J.D. (2004). Tourists' characteristics and the perceived image of tourist destinations: A quantitative analysis - A case study of Lanzarote, Spain. Tourism Management, 25, 623-636.

Buchmann, A., Moore, K., \& Fisher, D. (2010). Experiencing film tourism: authenticity and fellowship. Annals of Tourism Research, 37(1), 229-248.

Burns, P.M. (2004). Six postcards from Arabia: a visual discourse of colonial travels in the Orient. Tourist Studies, 4(3), 255-275.

Chaney, D. (1993). Fictions of Collective Life: Public drama in Late Modern Culture. London: Routledge.

Carey, J.W. (1988). Media, Myths, and Narratives. Television and the Press. Newbury Park: Sage Publications.

Carl, D., Kindon, S. and Smith, K. (2007) Tourists' experience of film locations: New Zealand as Middle-Earth. Tourism Geographies, 9, 49-63.

Carroll, N. (1996). Theorizing the moving image Cambridge. Cambridge University Press.

Crang, M. (1996) Magic Kingdom or a quixotic quest for authenticity. Annals of Tourism Research, 23(2), 415-431.

Crang, M. (1997). Picturing practices: research through the tourist gaze. Progress in Human Geography, 21(3), 359-373.

Creeber, G. (2001). Taking our personal lives seriously: intimacy, continuity and memory in the television drama serial Media, Culture and Society, 23(4), 439-455.
Dahles, H. (2002). The politics of tour guiding: image management in Indonesia. Annals of Tourism Research, 29 (3), 783-800.

Denzin, N.K. and Lincoln, Y.S. (2005) Introduction: The discipline and practice of qualitative research. In: Denzin, N.K. and Lincoln, Y. S., Eds. Handbook of Qualitative Research, 3rd Edition, Thousand Oaks: Sage, 1-32.

Edensor, T. (2000). Staging tourism: tourists as performers. Annals of Tourism Research, 27(2), 322-344.

Edensor, T. (2001). Performing tourism, staging tourism: (re)producing tourist space and practice. Tourist Studies, 1(1), pp. 59-81.

Evans D. (2008). Social media marketing an hour a day. Canada: Wiley Publishing, Inc.

Friedberg, A. 1998. The mobilized and virtual gaze in modernity: flâneur/flâneuse. The visual culture reader, edited by N Mirzhoeff. London: Routledge.

Fyall, A., Fletcher, J. and Spyriadis, T. (2010) Diversity, devolution and disorder: the management of tourism destinations. In: Kozak, M., Gnoth, J. and L. Andreu (eds) Advances in Tourism Destination Marketing: Managing Networks. United Kingdom: Routledge.

Giles, D. (2002) Parasocial interaction: a review of the literature and a model for future research. Media Psychology, 4, 279-305.

Haldrup, M and Larsen, J. (2003) The family gaze. Tourist Studies, 3(1), 23-45.

Hennig-Thurau, T., Gwinner, K. P., Walsh, G. \& Gremler, D. D. (2004). Electronic erode-of-mouth via consumer-opinion platforms: What motivates consumers to articulate themselves on the internet? Journal of Interactive Marketing, 18, 38- 52 .

Hobson, D. (2003). Soap opera. Cambridge: Polity Press.

Horne, D. (1984). The great museum. London: Pluto Press.

Hung, K., Stella, H., \& Li, Y. Y. (2007). The influence of e WOM on virtual consumer communities: Social capital, consumer learning, and behavioral outcomes. Journal of Advertising Research, 47(4), 485-495.

Kim, S. (2010) Extraordinary experience reenacting and photographing at screen tourism locations. Tourism and Hospitality Planning \& Development, 7:1, 59-75,

Kincaid, D.L. (2002) Drama, emotion, and cultural convergence. Communication Theory, 12(2), $136-152$.

Kuric, N. (2016). Social media and promotion of tourist destinations with negative country image. Thesis. 
Faculty of Economics and Social Sciences. University of Fribourg.

Lash, S. (1990). Sociology of Postmodernism. United Kingdom: Routledge.

Litvin, S. W., Goldsmith, R. E., \& Pan, B. (2008). Electronic word-of-mouth in hospitality and tourism management. Tourism Management, 29(3), 458468.

Macionis, Niki (2004) "Understanding the filminduced tourist". In Frost, Warwick, Croy, Glen and Beeton, Sue (eds.). International tourism and media conference proceedings. 24th-26th November 2004. Melbourne: Tourism Research Unit, Monash University. 86- 97.

Markwick, M. (2003). Postcards from Malta: image, consumption, context. Annals of Tourism Research, 28(2), 417-438.

Megah, I. U. (2017). The impact of AADC 2 in sellie coffee. Skripsi. Universitas Muhammadiyah Yogyakarta.

Miles, M.B., and Huberman, A.M. (1984). Qualitative data analysis. Newbury Park: Sage.

Miles, M.B, and Huberman, A.M. (1994). Qualitative data analysis, 2nd Ed., Newbury Park, CA: Sage

Lash, S. and Urry, J. (1994). Economics of signs and spaces. London: Sage Publications.

Mordue, T. (2001). Performing and directing resident/ tourist cultures in heartbeat country. Tourist Studies, 1(3), 233-252.

Morgan, N. and Pritchard, A. (2005). On souvenirs and metonymy: narratives of memory, metaphor and materiality. Tourist Studies, 5(1), 29-53.

Newcomb, H. (1974). TV: The most popular art. New York: Anchor.
Peeters, S, Urru, J.and DAHLES, H. (1999). A home away from home? The production and consumption of budget accommodations in two tourist areas in the city of Yogyakarta. In Dahles, H. and Bras, K. (eds), Tourism and Small Entrepreneurs. New York: Cognizant Communication.

Reijnders, S. (2016). Stories that move: fiction, imagination, tourism. European Journal of Cultural Studies, 19(6), 672-689.

Robinson, P., Lück, M. and Smith, S. (2013). Tourism. Oxfordshire: CABI.

Roesch, S. (2009). The experiences of film location tourists. Bristol: Channel View Publication

Shields, R. (1991). Places on the margin: alternative geographies of modernity. London: Routledge.

Thevenot, G. 2007. Blogging as social media. Tourism and Hospitality Research, 7, 287-289.

Timothey, D. and Wall, G. (1995). Tourist accommodation in an Asian historic city. Journal of Tourism Studies, 6 (2): 63-73.

Urry, J. (1990). The tourist gaze: leisure and travel in contemporary studies. London: Sage Publications.

Urry, J. (1994). Cultural change and contemporary tourism. Leisure Studies, 13, 233-238.

Valaskivi, K. (2000). Being a part of the family? Genre, gender and production in a Japanese TV drama. Media, Culture and Society, 22(3), 309-325.

W. Glynn Mangold and David J. Faulds, (2009). Social media: The new hybrid element of the promotion mix. Business Horizons, 52, (4), 357-365.

Wang, L., Liu, J., Li, X., Shi, J., Hu, J., Cui, R., ... Chen, Y. (2011). Growth propagation of yeast in linear arrays of microfluidic chambers over many generations. Biomicrofluidics, 5(4), 44118 441189. doi:10.1063/1.3668243 